Voix et Images

voixetimages

\title{
Le prêchi-prêcha du nouveau masculinisme
}

\section{Bernard Andrès}

Volume 8, numéro 3, printemps 1983

Jacques Ferron

URI : https://id.erudit.org/iderudit/200410ar

DOI : https://doi.org/10.7202/200410ar

Aller au sommaire du numéro

\section{Éditeur(s)}

Université du Québec à Montréal

ISSN

0318-9201 (imprimé)

1705-933X (numérique)

Découvrir la revue

Citer ce compte rendu

Andrès, B. (1983). Compte rendu de [Le prêchi-prêcha du nouveau

masculinisme]. Voix et Images, 8(3), 523-524. https://doi.org/10.7202/200410ar d'utilisation que vous pouvez consulter en ligne.

https://apropos.erudit.org/fr/usagers/politique-dutilisation/ 


\title{
THEẢTRE
}

\section{Le prêchi-prêcha du nouveau masculinisme}

\author{
par Bernard Andrès, Université du Quóbec à Montróal
}

Une reprise a l'aube de 83 , au Théâtre d'aujourd'hui: Roméo et Julien.! Après la comédie féminine Mon homme, qui avait ouvert la saison, une comédie "masculiniste" démarrait en janvier. L'une et l'autre semblaient se faire signe, du coin de l'oeil narquois de Jean-Claude Germain. Comme si la programmation tenait à équilibrer les extrêmes et à miser sur les deux tableaux. Mon homme et Roméo et Julien se renvoyaient en quelque sorte la balle. En fait, il s'agissait de deux spectacles bien différents, non seulement sur le plan des idées, mais surtout au niveau de la mise en forme et de l'intégration des points de vue au jeu scénique. De part et d'autre, un montage de sketches inégaux. Mon homme hésite entre la dérision et l'éloge du mâle. Roméo évoque "des choses importantes à changer entre les hommes et entre les hommes et les femmes". L'heure de la réconciliation a sonné, l'Hornme est mort, vive l'homme!... Réconciliation un peu hâtive dans un cas comme dans l'autre. Le contentieux est-il vraiment réglé?

Le montage des textes de femmes permettait d'en douter lla pièce était écrite par Suzanne Aubry, Elisabeth Bourget et Maryse Pelletier). La comédie de Jacques Girard et Reynald Robinson (créee voici trois ans à Québec) est plus convaincante. C'est surtout qu'elle articule infiniment mieux les sketches, avec un rythme et un allant qui emportent facilement notre adhésion au seul niveau du spectacie. Les tableaux, à peine brossés, se fondent aisément l'un dans l'autre autour des figures centrales des deux comédiens. De méme, la fonction du musicien. Pierre Potvin, n'est pas de pur accompagnement. Les chansons interprétées et accompagnées par les trois intervenants, se fondent naturellement dans l'ensemble. Si telle ou telle scène pèche par quelque gratuité (les cow-boys, le père et le fils), elle ne s'impose pas longtemps, aussitôt emportée par la suivante. Une bonne humeur, un bon humour nous la font aussitôt oublier. Tout comme on ne s'attarde pas sur la parodie lobligée pour les besoins du titrel de la scène des balcons, de Shaskespeare, ou sur le pastiche de tel auto-portrait de Boris Vian, au tout début. 
Se détachent alors les scènes de l'enfant de choeur (im)pénitent, de l'homme et de son double (rapport au sexe masculin), de la masturbation "technique" et de la tendre agressivité pugiliste. Ce qui frappe le plus, c'est l'invention du metteur en scène qui visualise chacune des séquences, insistant plus sur le jeu de l'acteur que sur le texte, au demeurant secondaire. Ainsi du duo presque monstrueux constitué par l'homme et son sexe. Collés l'un à l'autre, les deux comédiens miment plus qu'ils n'énoncent le rapport ambigu du måle et de son pénis. Autonomie relative des deux, soumission respective de l'un à l'autre, pesanteur des comportements obligés, etc. Là se trouvent révélées par l'oeil et pour l'oeil, des choses que vous avez toujours voulu savoir, mesdames, et que vous n'avez jamais osé reconnaitre, messieurs. Que dire des tattonnements adolescents en matière de masturbation (habilement mis-en-gestes, avec tout le "doigté" requis, par Claude Binet)? Quant à la tendresse contenue dans le corpsa-corps des lutteurs, elle se passe presque des paroles échangées entre les comédiens. C'est là peut-étre que résident les petites réussites du show: savoir rester spectaculaire, visuel, pathétique, sans abuser des mots. C'est ausisi bien là qu'il échoue, quand, à la toute fin, il dérape lamentablement dans le préchi-prêcha du nouveau masculinisme (parlons-nous-touchonsnous-pour-mieux-parler-toucher-les femmes...). Alors tout se fige au garde-àvous des déclamations solennelles et l'on regrette amèrement que le metteur en scène ne soit pas intervenu avant les cinq dernières minutes. Coupez!

1. Roméo et Julien, de Reynald Robinson et Jacques Girard. Par le Théătre de la Bordée. Mise en scène de Claude Binet. Avec Jacques Leblanc, Jacques Girard et Pierre Potvin. Au théztre d'Aujourd'hui (janvier-fóvrier 1983). 